\title{
Composição química de silagem e feno de Gliricídia sepium em diferentes alturas de resíduo
}

Chemical composition of silage and hay "Gliricidia sepium" in different residue heights

\author{
CARVALHO, Chrislanne Barreira de Macêdo ${ }^{1 *}$; SILVA, Shirlenne Ferreira ${ }^{2}$; \\ CARNEIRO, Maria Socorro de Souza ${ }^{2}$; EDVAN, Ricardo Loiola ${ }^{1}$; PEREIRA, Elzânia \\ Sales $^{2}$
}

${ }^{1}$ Universidade Federal do Piauí, Campus Professora Cinobelina Elvas, Programa de Pós-Graduação em Zootecnia, Bom Jesus, Piauí, Brasil.

${ }^{2}$ Universidade Federal do Ceará, Centro de Ciência Agrárias, Departamento de Zootecnia, Fortaleza, Ceará, Brasil.

*Endereço para correspondência: chrislanne_carvalho@hotmail.com

\section{RESUMO}

Objetivou-se avaliar a qualidade química de silagem e feno de gliricídia em diferentes alturas de resíduo. Utilizou-se delineamento experimental em blocos ao acaso em esquema fatorial $(3 \times 2)$, constando de três alturas de resíduo $(70,90$ e $110 \mathrm{~cm})$ e dois procedimentos de conservação de forragem (silagem e fenação) com quatro repetições. Para os valores de $\mathrm{pH}$ da gliricídia in natura e silagem não diferiram em relação à altura de resíduo, diferente dos teores de nitrogênio amoniacal $\left(\mathrm{N}-\mathrm{NH}_{3}\right)$, onde na altura de $70 \mathrm{~cm}$, apresentaram menores valores. As alturas de corte não influenciaram as perdas por gases, efluentes e recuperação da matéria seca da silagem de gliricídia. O feno apresentou maiores teores de proteína bruta (PB). $\mathrm{O}$ menor valor de matéria seca (MS) a $70 \mathrm{~cm}$ para o feno, conferiu-lhe menor acúmulo de massa seca, apresentando ainda, valores superiores de extrato etéreo (EE) e fibra detergente neutro $(F D N)$ em relação à silagem para as alturas de 70 e $90 \mathrm{~cm}$. A planta mantida em altura mais elevada $(110 \mathrm{~cm})$, acumulou maior EE $\mathrm{e}$ concentração de material fibroso. A silagem de gliricídia apresenta valores adequados de $\mathrm{pH}$ independente da altura residual, assim como não influenciam as perdas fermentativas da silagem, no entanto, há perdas elevada de $\mathrm{N}-\mathrm{NH}_{3}$ para altura residual $110 \mathrm{~cm}$. MS, EE e FDN sofrem influência das alturas de resíduos, assim como pelos métodos de conservação.

Palavras-chave: conservação, forragem, leguminosa, ruminantes

\section{SUMMARY}

This study aimed to evaluate the chemical quality of silage and hay Gliricídia in different residue heights. The experimental design in randomized blocks in a factorial scheme $(3 \times 2)$, consisting of three residue heights $(70,90$ and $110 \mathrm{~cm})$ and two forage conservation procedures (silage and hay) with four replications. For $\mathrm{pH}$ values Gliricídia fresh and silage did not differ in relation to waste time, unlike the concentration of ammonia nitrogen $\left(\mathrm{NH}_{3}-\mathrm{N}\right)$, where the height of $70 \mathrm{~cm}$, had lower values. The cutting height did not influence gas losses, effluents and recovery of dry matter silage Gliricídia. Hay had higher crude protein $(\mathrm{CP})$. The lowest dry matter (DM) and $70 \mathrm{~cm}$ for the hay, gave him less accumulation of dry matter, with still higher values of ether extract (EE) and neutral detergent fiber (NDF) in relation to silage for heights 70 and $90 \mathrm{~cm}$. The plant was maintained at a higher height (110 $\mathrm{cm})$, EE and accumulated higher concentration of fibrous material. Silage Gliricídia provides suitable $\mathrm{pH}$ values independent of the residual time, and does not influence the fermentation losses of silage, however, there are high losses of NH3 for residual height $110 \mathrm{~cm}$. DM, EE and NDF are influenced heights of waste, as well as the conservation methods.

Keywords: conservation, forage, legumes, ruminants 


\section{INTRODUÇÃO}

Nas regiões semiáridas brasileiras, como maneira de utilização do excedente de forragens no período favorável do ano, o uso de silagem e feno tem aumentado significadamente na produção animal, consequentemente diminuindo a escassez de alimento durante o período seco. De acordo com Edvan et al. (2016), a Gliricídia é uma espécie de grande interesse comercial e econômico para regiões tropicais pelas suas características de uso múltiplo, sendo assim, uma espécie forrageira com grande potencial para essa região.

A gliricídia (Gliricidia sepium) é uma leguminosa arbórea, resistente à seca, que vem sendo cultivada como fonte de forragem em propriedades rurais no Semiárido nordestino (PÉREZ MARIN et al., 2007), devido sua capacidade de rebrota, elevada produtividade em banco de proteína, e por suportar cortes periódicos, tem apresentado grande importância na produção de volumoso de qualidade. Cabral Junior et al. (2007) relata que suas folhas possuem alto teor de proteína bruta, geralmente acima de $20 \%$.

Apesar da alta qualidade como forragem e da elevada produção de biomassa, seu uso in natura pode ser limitado devido ao odor provocado pela liberação de compostos voláteis de suas folhas e sua possível toxidez, principalmente para animais não ruminantes (COSTA et al., 2009), não sendo prontamente aceita nos primeiros fornecimentos. Em geral, procedimentos como a ensilagem e fenação, podem melhorar sua aceitabilidade por parte dos animais, em especial pelos poligástricos. Determinar qual técnica de conservação proporciona melhor alimento conservado para as plantas forrageiras é prática importante, para a tomada de decisão na propriedade rural.

Essa espécie apresenta ainda, baixo teor de carboidratos solúveis e de matéria seca. Todas essas características podem comprometer sua conservação, e são influenciadas pelo manejo de corte. Dessa forma, este trabalho foi desenvolvido com objetivo de avaliar a qualidade química da silagem e do feno de Gliricidia sepium em diferentes alturas de resíduo.

\section{MATERIAL E MÉTODOS}

O experimento foi desenvolvido no Setor de Forragicultura do Departamento de Zootecnia da Universidade Federal do Ceará - UFC, em Fortaleza - CE. O município de Fortaleza situa-se na Zona Litorânea, a $21 \mathrm{~m}$ de altitude, $3^{\circ} 43^{\prime} 02^{\prime \prime}$ de Latitude Sul e 38०32'35" de Longitude Oeste. Segundo a classificação de Köeppen, o clima é do tipo Aw, tropical chuvoso, com chuvas principalmente no verão, com precipitação pluviométrica média anual em torno de $800 \mathrm{~mm}$, distribuída no período de janeiro a abril. Foi utilizada uma área de $600 \mathrm{~m}^{2}$ já implantada de Gliricídia sepium, desde 2010.

$\mathrm{O}$ delineamento experimental foi em blocos ao acaso em esquema fatorial (3x2), os fatores constaram de três alturas de resíduo, acima do nível do solo $(70,90$ e $110 \mathrm{~cm})$ e dois procedimentos de conservação de forragem (silagem e fenação) com quatro repetições.

O corte de uniformização com a aplicação dos tratamentos foi realizado em dezembro de 2013 para fenação, sendo as plantas adubadas com $90 \mathrm{Kg}$ $\mathrm{ha}^{-1}$ de fosfato (superfosfato simples) e $60 \mathrm{Kg} \mathrm{ha}^{-1}$ de potássio (cloreto de 
potássio). Foram confeccionados silagem e feno, após 90 dias do corte de uniformização. As plantas foram cortadas de acordo com os tratamentos $(70,90$ e $110 \mathrm{~cm})$, utilizando tesouras de poda e serrote de jardim. Em seguida todo o material foi recolhido separandose as folhas e ramos com até $1 \mathrm{~cm}$ de diâmetro.

Para produção de silagem, o material foi coletado, identificado e armazenado em sacos plásticos, sendo picado em máquina forrageira. $\mathrm{O}$ material picado foi colocado em silos experimentais confeccionados com baldes de aproximadamente três litros, com válvula tipo bunsen adaptada em sua tampa, para permitir o escape dos gases oriundos da fermentação. No fundo de cada balde foi depositado $1 \mathrm{~kg}$ de areia, separados da forragem por uma camada de tecido de algodão, sendo possível medir a quantidade de efluentes retida. Todo o material foi compactado, de modo a atingir uma densidade de aproximadamente $550 \mathrm{Kg} \quad \mathrm{m}^{-3}$. Posteriormente, os silos foram vedados com fitas adesivas sendo registrados seus pesos, e acomodados na sala de preparo de amostras do setor de Forragicultura. No fechamento, e na abertura dos silos após 30 dias, foram retiradas amostras de cada tratamento, sendo estas pesadas com aproximadamente 500g, acondicionadas em sacos devidamente identificados, para a realização das análises de $\mathrm{pH}$ e nitrogênio amoniacal
$\left(\mathrm{N}-\mathrm{NH}_{3}\right)$, de acordo com a metodologia descrita por Mizubuti et al. (2009).

Antes da abertura, os silos foram pesados, para posterior determinação das perdas de matéria seca (MS) na forma de gases e efluentes e a recuperação de matéria seca (RMS), segundo equações descritas por Zanine et al. (2010).

Para produção do feno, as plantas foram cortadas de acordo com cada tratamento pela manhã, seguido da picagem em máquina estacionária ensiladeira modelo JF 50 MAXXIUM, e posteriormente exposto ao sol em lonas plásticas separadas por tratamentos, revolvido a cada 1 hora até atingir o ponto de feno $(80 \%$ matéria seca). Durante a desidratação, foi retirada uma amostra com cerca de 500 g para cada tratamento, para posterior análise.

Foram determinados os teores de matéria seca (MS), proteína bruta (PB), matéria mineral $(\mathrm{MM})$, extrato etéreo (EE), fibra em detergente neutro (FDN) e fibra em detergente ácido (FDA), segundo a metodologia descrita por Silva \& Queiroz (2002). Todas as análises foram realizadas no Laboratório de Nutrição Animal do Departamento de Zootecnia da Universidade Federal do Ceará. Para obter os dados de composição química da planta in natura antes de ensilar e fenar (Tabela 1), o material foi colhido nas diferentes alturas de resíduo e foi feito uma amostra composta para análise.

Tabela 1. Composição química da gliricídia in natura

\begin{tabular}{|c|c|c|c|c|c|}
\hline \multirow{2}{*}{$\begin{array}{l}\text { MS } \\
\mathrm{g} \mathrm{kg}^{-1}\end{array}$} & PB & MM & $\mathrm{EE}$ & FDN & FDA \\
\hline & \multicolumn{5}{|c|}{$\mathrm{g} \mathrm{kg}^{-1} \mathrm{MS}$} \\
\hline 290,6 & 202,3 & 56,1 & 46,6 & 615,9 & 381,5 \\
\hline
\end{tabular}


Os dados foram submetidos à análise de variância, utilizando o software SISVAR versão 5.0 desenvolvido pela Universidade Federal de Lavras (FERREIRA, 2011). A comparação de médias foi realizada através do teste de Tukey, adotando-se 5\% de nível de significância.

\section{RESULTADOS E DISCUSSÃO}

Para os valores de $\mathrm{pH}$ da gliricídia in natura e silagem não houve diferença $(\mathrm{P}>0,05)$ em relação à altura de resíduo empregada (Tabela 2). Esse fato demonstra que a massa de forragem obtida através de manejo diferenciado provavelmente não proporciona diferença no processo fermentativo da massa de forragem ensilada, provavelmente devido ao teor de matéria seca do material (MS) antes de ensilar que foi de 290,6 $\mathrm{gg}^{-1}$ (Tabela 1). Para o $\mathrm{pH}$ do material in natura $\mathrm{e}$ silagem, os valores encontrados nesse trabalho, estão dentro do preconizado por Tomich et al. (2004) ao afirmarem que valores na faixa de $\mathrm{pH}$ ente $3,2 \mathrm{e}$ 4,2 são considerados adequados às silagens bem conservadas, pois nessa faixa, ocorre a restrição de enzimas proteolíticas da planta e de enterobactérias e clostrídeos que são indesejáveis no processo fermentativo.
Houve diferença significativa para os teores de $\mathrm{N}-\mathrm{NH}_{3}$ (nitrogênio amoniacal) em relação ao material in natura $\mathrm{e}$ silagem da gliricídia para as alturas residuais de 70,90 e $110 \mathrm{~cm}$. Segundo McDonald et al. (1991), na forragem fresca, aproximadamente 75 a $90 \%$ do nitrogênio total está presente na proteína, estando o restante na forma de peptídeos, aminoácidos livres, amidas, clorofila e nitratos. A quantidade de $\mathrm{N}$ $\mathrm{NH}_{3}$ livre corresponde, normalmente, a menos de $1 \%$ do nitrogênio total. Os valores de $\mathrm{N}-\mathrm{NH}_{3}$ para a silagem de gliricídia variaram de 7,0 a $8,5 \%$. Diferente de Silva et al. (2015), que ao avaliarem a composição química das silagens de forrageiras lenhosas do Semiárido brasileiro, encontraram valores de 10,93\% para a silagem de gliricídia.

$\mathrm{Na}$ silagem, de acordo com Van Soest (1994), um baixo teor de nitrogênio amoniacal, inferior a $10 \%$ do nitrogênio total, indica que o processo de fermentação não resultou em quebra excessiva da proteína em amônia, e os aminoácidos constituem a maior parte do nitrogênio não-protéico. Em contra partida, um teor de $\mathrm{N}-\mathrm{NH}_{3}$ superior a $15 \%$ do nitrogênio total significa que a quebra de proteínas foi considerável, e nesses casos, as silagens podem ser menos aceitas pelos animais, resultando em baixo consumo.

Tabela 2. Valores de $\mathrm{pH}$ e nitrogênio amoniacal $\left(\mathrm{N}-\mathrm{NH}_{3}\right)$ da gliricídia in natura e silagem em três alturas de resíduo

\begin{tabular}{lcccc}
\hline \multirow{2}{*}{ Altura de resíduo } & $\mathrm{pH}$ & $\mathrm{NH}$ & \multicolumn{2}{c}{$\mathrm{NH}_{3}(\%)$} \\
\cline { 2 - 5 } & \multicolumn{2}{c}{ In natura } & Silagem & \\
\hline $70 \mathrm{~cm}$ & $5,41^{\mathrm{a}}$ & $\left.2,2^{\mathrm{b}}\right)$ & $3,98^{\mathrm{a}}$ & $7,7^{\mathrm{ab}}$ \\
$90 \mathrm{~cm}$ & $5,56^{\mathrm{a}}$ & $3,5^{\mathrm{a}}$ & $3,90^{\mathrm{a}}$ & $7,0^{\mathrm{b}}$ \\
$110 \mathrm{~cm}$ & $5,37^{\mathrm{a}}$ & $3,5^{\mathrm{a}}$ & $3,91^{\mathrm{a}}$ & $8,5^{\mathrm{a}}$ \\
\hline EPM $^{1}$ & 0,04 & 0,20 & 0,04 & 0,18 \\
\hline
\end{tabular}

Médias com mesma letra minúscula na linha, não diferem entre si pelo teste de Tukey, ao nível de 5\% probabilidade.

${ }^{1} \mathrm{EPM}=$ erro-padrão da média. 
Os valores de $\mathrm{N}-\mathrm{NH}_{3}$ no momento da abertura do silo estão dentro do preconizado por McDonald et al. (1981), onde enfatizam que para que uma silagem seja considerada de boa qualidade, esta deve apresentar teores de $\mathrm{N}-\mathrm{NH}_{3}$ com $12 \%$, que é o limite superior para se classificar as silagens como de boa qualidade. Os menores teores de $\mathrm{N}_{-} \mathrm{NH}_{3}$ encontrados em silagens indicam que as perdas de nitrogênio na forma de amônia foram baixas, sugerindo que todas as etapas no processo de ensilagem até o enchimento do silo foram realizadas de maneira satisfatória.
As alturas de corte não influenciaram as perdas por gases, efluentes e recuperação da matéria seca da silagem de gliricídia (Tabela 3). Os valores encontrados para as perdas por gases nesse estudo estão baixos, onde Pupo (2002), relata que os parâmetros de perdas gasosas podem atingir de 2 a $5 \%$ da matéria seca inicial. De acordo com McDonald et al. (1991), o aumento significativo nas perdas por gases ocorre quando há produção de álcool (etanol ou mantinol) por fermentação por bactérias heterofermentativas, enterobactérias, leveduras e bactérias no gênero Clostridium ssp.

Tabela 3. Perdas por gases, efluentes e recuperação da matéria seca em silagem de Gliricídia sepium em três alturas de resíduo

\begin{tabular}{lcccc}
\hline \multirow{2}{*}{ Variáveis } & \multicolumn{4}{c}{ Altura de resíduo } \\
\cline { 2 - 5 } & $70 \mathrm{~cm}$ & $90 \mathrm{~cm}$ & $110 \mathrm{~cm}$ & EPM $^{2}$ \\
\hline Gases & $0,46^{\mathrm{a}}$ & $0,41^{\mathrm{a}}$ & $0,37^{\mathrm{a}}$ & 0,06 \\
Efluentes & $13,27^{\mathrm{a}}$ & $12,12^{\mathrm{a}}$ & $10,49^{\mathrm{a}}$ & 0,88 \\
RMS $^{1}$ & $89,66^{\mathrm{a}}$ & $90,33^{\mathrm{a}}$ & $90,86^{\mathrm{a}}$ & 0,85 \\
\hline
\end{tabular}

Médias com mesma letra minúscula na linha, não diferem entre si pelo teste de Tukey, ao nível de 5\% probabilidade.

${ }^{1} \mathrm{RMS}=$ recuperação da matéria seca; ${ }^{2} \mathrm{EPM}=$ erro-padrão da média.

Em relação aos efluentes produzidos durante $o$ processo de fermentação, variaram de 10,49 a $13,37 \%$. Mcdonald (1981) afirma que perdas por efluentes podem variar de 7 até valores próximos a $40 \%$, sendo considerados aceitáveis. Como formas de diminuição das perdas por efluente, podem-se utilizar técnicas como o emurchecimento e aplicação de aditivos absorventes da umidade (ZANINE et al., 2006), o que não foi necessário nesse estudo. Em relação a recuperação de matéria seca (RMS) a gliricídia apresentou no momento do corte teor de umidade próximo do adequado para ser ensilada (Tabela 1), esta não influenciou $\mathrm{o}$ processo de fermentação, permitindo obter teores de matéria seca considerados satisfatórios para uma silagem bem conservada, sem necessidade de aditivos. Santos et al. (2010) nos seus estudos sobre valor nutritivo de silagens de forrageiras tropicais, evidenciam que o uso de aditivos absorvente é capaz de proporcionar elevação do teor de MS do material ensilado e promover ambiente menos favorável para o desenvolvimento das leveduras, contribuindo também para menores perdas por efluentes.

Não houve efeito de interação entre os fatores (altura de resíduo x métodos de conservação) para matéria mineral (MM), fibra em detergente ácido (FDA) e proteína bruta (PB). Os valores de FDA da Gliricídia sepium, foram 
influenciados pelas alturas de resíduo, sendo a altura residual de $90 \mathrm{~cm}$ apresentando maior valor $\left(473,1 \mathrm{~g} \mathrm{~kg}^{-1}\right)$. Silva et al. (2015) enfatiza que altos teores de FDA são indesejáveis, uma vez que indicam a presença de constituintes lignocelulósicos, pouco aproveitados pelos animais $\mathrm{e}$ negativamente correlacionados com a digestibilidade da matéria seca.
Em relação aos métodos de conservação, silagem e feno, foi observado efeito para os valores FDA e PB (Tabela 4). A maior quantidade de FDA está presente na silagem. Assim como estudos de diversos autores (COAN et al., 2007; EVANGELISTA et al., 2009), o aumento no conteúdo da parede celular, deve-se ao consumo dos carboidratos solúveis pelos microrganismos durante $\mathrm{o}$ processo de fermentação.

Tabela 4. Valores de matéria mineral, fibra em detergente ácido e proteína bruta da Gliricídia sepium em três alturas de resíduo de acordo com métodos de conservação.

\begin{tabular}{|c|c|c|c|c|}
\hline Item & \multicolumn{2}{|c|}{$\mathrm{MM}^{2}$} & FDA $^{3}$ & $\mathrm{~PB}^{4}$ \\
\hline $\mathrm{P}<$ Altura de resíduo (alt.) & \multicolumn{2}{|c|}{0,5325} & 0,0219 & 0,3450 \\
\hline $\mathrm{P}<$ Métodos de conservação (MC) & \multicolumn{2}{|c|}{0,7559} & 0,0002 & 0,0001 \\
\hline $\mathrm{P}<$ Alt. $\mathrm{x} \mathrm{MC}$ & \multicolumn{2}{|c|}{0,9313} & 0,3814 & 0,8578 \\
\hline $\mathrm{CV}(\%)$ & \multicolumn{2}{|c|}{17,16} & 7,95 & 8,73 \\
\hline \multirow{3}{*}{ Variáveis } & \multicolumn{4}{|c|}{ Métodos de conservação } \\
\hline & \multicolumn{2}{|c|}{ Silagem } & Feno & \multirow{2}{*}{$\mathrm{EPM}^{1}$} \\
\hline & \multicolumn{3}{|c|}{$\mathrm{g} \mathrm{kg}^{-1} \mathrm{MS}$} & \\
\hline${ }^{2}$ Matéria mineral (MM) & & & $63,4^{\mathrm{a}}$ & 3,1 \\
\hline${ }^{3}$ Fibra em detergente ácido (FDA) & 48 & & $417,3^{b}$ & 7,4 \\
\hline${ }^{4}$ Proteína bruta $(\mathrm{PB})$ & & & $203,2^{\mathrm{a}}$ & 4,6 \\
\hline \multirow{3}{*}{ Variáveis } & \multicolumn{4}{|c|}{ Altura de resíduo } \\
\hline & $70 \mathrm{~cm}$ & $90 \mathrm{~cm}$ & $110 \mathrm{~cm}$ & \multirow{2}{*}{$\mathrm{EPM}^{1}$} \\
\hline & \multicolumn{3}{|c|}{$\left(\mathrm{g} \mathrm{kg}^{-1} \mathrm{MS}\right)$} & \\
\hline${ }^{2}$ Matéria mineral $(\mathrm{MM})$ & $63,0^{\mathrm{a}}$ & $62,5^{\mathrm{a}}$ & $61,6^{\mathrm{a}}$ & 3,8 \\
\hline${ }^{3}$ Fibra em detergente ácido (FDA) & $464,5^{\mathrm{ab}}$ & $473,1^{\mathrm{a}}$ & $420,2^{\mathrm{b}}$ & 12,7 \\
\hline${ }^{4}$ Proteína bruta $(\mathrm{PB})$ & $185,1^{\mathrm{a}}$ & $179,8^{\mathrm{a}}$ & $192,0^{a}$ & 5,7 \\
\hline
\end{tabular}

O feno de gliricídia apresentou maior teor de $\mathrm{PB}$ em relação à silagem. A rápida desidratação do material no processo de fenação favoreceu a conservação desse nutriente sem maiores perdas. Perdas durante 0 processo de fermentação das silagens não são interessantes, já que ocorre a degradação de proteínas, peptídeos, aminas e amidas e ocorrência de amônia (McDONALD, 1981), o que acarreta má qualidade da silagem. Diferentes desses resultados, Edvan et al. (2013) encontraram um valor de $205,5 \mathrm{~g} \mathrm{~kg}^{-1}$ de PB para silagem de gliricídia com nível de $0 \%$ de vagem de algaroba. No entanto, os teores PB encontrados neste trabalho estão dentro do preconizado pela literatura para nutrição de ruminantes, indicando que não comprometeram o valor nutricional da silagem.

Houve interação entre os fatores altura de resíduo e métodos de conservação 
para os teores de matéria seca (MS), extrato etéreo (EE) e fibra em detergente neutro (FDN) (Tabela 5). Observou-se que o teor de MS na altura residual de $70 \mathrm{~cm}$ do feno, apresentou menor valor em relação à silagem, o que pode estar associado com a maior intensidade de corte sofrida pela planta, o que lhe conferiu um menor acúmulo de massa seca. Estando abaixo do preconizado para feno de boa qualidade, com teores de umidade entre 100 e $200 \mathrm{~g}$ $\mathrm{kg}^{-1}$ (MORAES \& RAMOS, 1998).
Nota-se, que as diferentes alturas não afetaram os valores médios de MS para silagem. Em suas pesquisas, Pires et al. (2009) relatam que elevado teor de umidade da forrageira, favorece $\mathrm{o}$ desenvolvimento de bactérias do gênero Clostridium, o que resulta em perdas na ensilagem. Esse baixo teor de MS se deu, possivelmente, porque o material usado para ser ensilado era constituído em sua grande parte por folhas separadas dos ramos (até $1 \mathrm{~cm}$ de diâmetro).

Tabela 5. Valores de matéria seca, extrato etéreo e fibra em detergente neutro (\% MS) para silagem e feno de Gliricidia sepium em relação à altura do corte

\begin{tabular}{|c|c|c|c|}
\hline & $\mathrm{MS}^{2}$ & $\mathrm{EE}^{3}$ & $\mathrm{FDN}^{4}$ \\
\hline $\mathrm{P}<$ Altura de resíduo (alt.) & 0,1008 & 0,1753 & 0,0001 \\
\hline $\begin{array}{l}\mathrm{P}<\text { Métodos de } \\
\text { conservação (MC) }\end{array}$ & $<0,0001$ & 0,0327 & 0,0004 \\
\hline $\mathrm{P}<$ Alt. $\times \mathrm{MC}$ & 0,0113 & 0,0051 & 0,0025 \\
\hline CV $(\%)$ & 5,28 & 11,33 & 2,91 \\
\hline \multicolumn{3}{|l|}{ Altura de resíduo } & \\
\hline Aitura de residuo & Silagem & & Feno \\
\hline \multicolumn{4}{|c|}{${ }^{2}$ Materia seca $\left(\mathrm{g} \mathrm{kg}^{-1}\right)$} \\
\hline $70 \mathrm{~cm}$ & $291,9^{\mathrm{bA}}$ & & $796,1^{\mathrm{aB}}$ \\
\hline $90 \mathrm{~cm}$ & $279,4^{\mathrm{bA}}$ & & $868,3^{\mathrm{aA}}$ \\
\hline $110 \mathrm{~cm}$ & $274,3^{\mathrm{bA}}$ & & $873,6^{\mathrm{aA}}$ \\
\hline EPM & & 14,8 & \\
\hline \multicolumn{4}{|c|}{${ }^{3}$ Extrato etéreo $\left(\mathrm{g} \mathrm{kg}^{-1} \mathrm{MS}\right)$} \\
\hline $70 \mathrm{~cm}$ & $35,1^{\mathrm{bB}}$ & & $47,1^{\mathrm{aA}}$ \\
\hline $90 \mathrm{~cm}$ & $38,2^{\mathrm{bB}}$ & & $46,4^{\mathrm{aA}}$ \\
\hline $110 \mathrm{~cm}$ & $48,8^{\mathrm{aA}}$ & & $42,7^{\mathrm{aA}}$ \\
\hline EPM & & 2,40 & \\
\hline \multicolumn{4}{|c|}{ gente neutro $(\mathrm{g} \mathrm{kg}$} \\
\hline $70 \mathrm{~cm}$ & $565,9^{\text {bB }}$ & \multirow{4}{*}{\multicolumn{2}{|c|}{$\begin{array}{l}624,1^{\mathrm{aA}} \\
644,6^{\mathrm{aA}} \\
639,4^{\mathrm{aA}}\end{array}$}} \\
\hline $90 \mathrm{~cm}$ & $579,9^{\mathrm{bB}}$ & & \\
\hline $110 \mathrm{~cm}$ & $644,3^{\mathrm{aA}}$ & & \\
\hline EPM & & & \\
\hline
\end{tabular}

Médias com mesma letra maiúscula na linha, e minúscula na coluna não diferem entre si pelo teste de Tukey, ao nível de $5 \%$ probabilidade.

$\mathrm{EPM}=$ erro-padrão da média.

O teor de extrato etéreo (EE) na altura de resíduo de $110 \mathrm{~cm}$ foi superior aos demais tratamentos apenas no tratamento com silagem, conforme os dados da Tabela 5, sugerindo que nessa altura nos dois métodos de conservação, o teor de gordura da planta é mantido sem perdas relevantes. Santos et al. (2010) ressalva que o valor dos nutrientes digestíveis totais das silagens diminuiu significativamente com o aumento do conteúdo de MS a partir de 
16 dias de estocagem, e como reflexo da tendência de aumento nos conteúdos de FDN, FDA, LIG, NIDN e NIDA e redução no teor de EE. De acordo com Van Soest (1994), o teor de extrato etéreo em até $80 \mathrm{~g} \mathrm{~kg}^{-1}$ na alimentação de ruminantes é aceitável, pois acima desse valor, pode ocorrer limitação no consumo de matéria seca pelo animal, valores estes não sendo obtidos neste estudo.

Os maiores valores encontrados referentes a fibra em detergente neutro (FDN) foram observado na silagem para a altura residual de $110 \mathrm{~cm}$, correspondendo a $644,3 \mathrm{~g} \mathrm{~kg}^{-1}$. O que pode estar associado à maior altura da planta e maior concentração de material fibroso, pois plantas arbóreas manejadas com maior altura de resíduo tendem a apresentar um maior crescimento. Em seus estudos com manejo de Paspalum dilatatum, Baréa et al. (2007) concluem que cortes em intervalos de 30 dias, a $10 \mathrm{~cm}$ da base das plantas, apresentam maior conteúdo de $\mathrm{PB}$ e menores teores de FDA e FDN, em decorrência da maior alocação de MS em folhas verdes. Além disso, teores de fibra elevados nas forragens dificultam $o$ consumo e digestibilidade pelo animal.

A silagem de gliricídia apresenta valores adequados de $\mathrm{pH}$, independente da altura residual, assim como não influenciam as perdas fermentativas, no entanto, há perdas de nitrogênio amoniacal elevada na altura de resíduo de $110 \mathrm{~cm}$.

Os teores de MS, FDN e EE além de sofrerem influência pelas alturas de resíduos, também são influenciados pelos métodos de conservação. A gliricídia conservada na forma de feno apresentou melhor qualidade química para o teores de PB e FDA em relação a silagem.

\section{REFERÊNCIAS}

\author{
BARÉA, K.; SCHEFFER-BASSO, \\ S.M.; DALL'AGNOL, M.; OLIVEIRA, \\ B.N. Manejo de Paspalum dilatatum \\ Poir. biótipo Virasoro. 1. Produção, \\ composição química e persistência.
} Revista Brasileira de Zootecnia, v.36, n.4, p.992-999, 2007.

CABRAL JR., E.C.; MIRANDA, C.R.; PINHEIRO, D.M.; GUIMARÃES, I.G.; ANDRADE, M.V.M.; PINTO, M.S.C. Dinâmica fermentativa de silagens de gliricidia sepium. Archivos de

Zootecnia, v.56, n.214, p.249-252, 2007.

COAN, R.M.; REIS, R.A.; GARCIA, G.R.; SCHOCKEN-ITURRINO, R.P.; FERREIRA, D.S.; RESENDE, F.D.; GURGEL, F.A. Dinâmica fermentativa e microbiológica de silagens dos capins Tanzânia e Marandu acrescidas de polpa cítrica peletizada. Revista

Brasileira de Zootecnia, v.36, n.5, p.1502-1511, 2007.

COSTA, B.M.; SANTOS, I.C.V.; OLIVEIRA, G.J.C.; PEREIRA, I.G. Avaliação de folhas de gliricidia sepium (Jacq.) Walp por ovinos. Archivos de Zootecnia, v.58, n.221, p.33-41, 2009.

EDVAN, R.L.; CARNEIRO, M.S.S.; COUTINHO, M.J.F.; SILVA, E.B.; OLIVEIRA, G.S.; SILVA, M.S.M.; ALBUQUERQUE, D.R. Perdas e composição bromatológica de silagem de gliricídia contendo diferentes níveis de vagem de algaroba. Tecnologia \& Ciência Agropecuária, v.7, n.2, p.6368, 2013. 
EDVAN, R.L.; CARNEIRO, M.S.S.; SILVA, E.B.; ALBUQUERQUE, D.R.; PEREIRA, E.S.; BEZERRA, L.R.; SILVA A.L.; ARAÚJO, M.J. Análise de crescimento da gliricídia submetida a diferentes manejos de corte.

Archivos de Zootecnia, v.65, n.250, p.163-169, 2016.

EVANGELISTA, A.R.; SIQUEIRA, G.R.; LIMA, J.A.; LOPES, J.; REZENDE, A.V. Perfil fermentativo de silagens de cana-de-açúcar com e sem inclusão de milho desintegrado com palha e sabugo. Revista

Brasileira de Zootecnia, v.38, n.1, p.20-26, 2009.

FERREIRA, D. F. SISVAR. Lavras: Universidade Federal de Lavras, 2011.

McDONALD, P. The Biochemistry of Silage. New York: John Willey \& Sons, 1981. 226p.

McDONALD, P.; HENDERSON, A.R.; HERON, S.J.E. The biochemistry of silage. $2 \mathrm{ed}$. Marlow: Chalcombe Pub, 1991. 340p.

MIZUBUTI, I.Y.; PINTO, A.P.; PEREIRA, E.S.; RAMOS, B.M.O. Métodos laboratoriais de avaliação de alimentos para animais. $1 \mathrm{ed}$. Londrina: EDUEL, 2009. 228p.

MORAES, E.A.; RAMOS, A.K.B. Produção de feno. Planaltina: Embrapa Cerrado, 1998. 6p.

PÉREZ HERNÁNDEZ, M. Fatores que afetam o valor nutritivo da silagens de forrageiras tropicais. Archivos de Zootecnia, v.59, n.(R), p.25-43, 2010.
PIRES, A.J.V.; CARVALHO, G.G.P.; GARCIA, R.; CARVALHO JUNIOR, J.N.; RIBEIRO L.S.O.; CHAGAS, D.M.T. Capim-elefante ensilado com casca de café, farelo de cacau ou farelo de mandioca. Revista Brasileira de Zootecnia, v.38, n.1, p.34-39, 2009.

PUPO, N.I.H. Manual de pastagens e forrageiras: formação, conservação, utilização. Campinas: Instituto Campineiro de Ensino Agrícola, 2002. p.274-303.

SANTOS, M.V.F.; GÓMEZ CASTRO, A.G.; PEREA, J.M.; GARCÍA, A.; GUIM, A.; PÉREZ MARIN, A.M.P.; MENEZES, R.S.C.; SALCEDO, I.H. Produtividade de milho solteiro ou em aléias de gliricídia adubado com duas fontes orgânicas. Pesquisa Agropecuária Brasileira, v.42, n.5, p.669-677, 2007.

SILVA, D.C.; QUEIROZ, A.C. Análise de alimentos: métodos químicos e biológicos. 3.ed. Viçosa: Universidade Federal de Viçosa, 2002, 235p.

SILVA, M.D.A.; CARNEIRO, M.S.S.; PINTO, A.P.; POMPEU, R.C.F.F.; SILVA, D.S.; COUTINHO, M.J.F.; FONTENELE, R.M. Avaliação da composição químico-bromatológica das silagens de forrageiras lenhosas do semiárido brasileiro. Semina: Ciências Agrárias, v.36, n.1, p.571-578, 2015.

TOMICH, T.R.; GONÇALVES, L.C.; RENATA GRAÇA PINTO TOMICH, R.G.P.; RODRIGUES, J.A.S.; BORGES, I.; RODRIGUEZ, N.M. Características Químicas e Digestibilidade in vitro de Silagens de Girassol. Revista Brasileira de Zootecnia, v.33, n.6, p.1672-1682, 2004. 
VAN SOEST, P.J. Nutritional ecology of the ruminant. Washington: Cornell Univertsity Press, 1994. 476p.

ZANINE, A.M.; SANTOS, E.M.;

FERREIRA, D.J.; OLIVEIRA, J.S.;

ALMEIDA, J.C.C.; PEREIRA, O.G.

Avaliação da silagem de capim elefante com adição de farelo de trigo. Archivos de Zootecnia, v.54, n.208, p.1-10, 2006 .

ZANINE, A.M; SANTOS, E.M., DÓREA, J.R.R.; DANTAS, P.A.S.; SILVA, T.C.; PEREIRA, O.G.

Evaluation of elephant grass silage with the addition of cassava scrapings.

Revista Brasileira de Zootecnia, v.39, n.12, p.2611-2616, 2010.

Data de recebimento: 15/09/2016

Data de aprovação: 17/05/2017 